\title{
SPATIAL DISTRIBUTION OF MICROPARTICLES WITHIN
}

\section{ANTARCTIC SNOW-FALL*}

\author{
by \\ Lonnie G. Thompson and Ellen Mosley-Thompson \\ (Institute of Polar Studies, Ohio State University, Columbus, Ohio 43210, U.S.A.)
}

ABSTRACT

The concentration and size distribution of waterinsoluble microparticles were measured in 2332 snow and firn samples from (a) two sites on the Antarctic Peninsula, (b) the Byrd station strain network, West Antarctica, (c) the $0-13$ and base camp sites on the Ross Ice Shelf, and (d) the South Pole and Dome C sites in East Antarctica. These near-surface microparticle studies indicate that, while the number of particles per unit volume of sample remains fairly uniform from site to site, the annual particle accumulation is greatest at locations nearest the coast and decreases rapidly with distance inland. The relationship between particle accumulation and distance from the coast is analogous to a relationship between snow accumulation and distance from the coast. Ten times more particles are deposited annually at stations within $50 \mathrm{~km}$ of the coast than at the South Pole and Dome $C$ sites. The size distribution data reveal that, with the possible exception of the $Q-13$ site, the particulates deposited in Antarctica are well-sorted, indicating little contribution from local sources.

\section{INTRODUCTION}

Antarctica is considered to be an ideal site for investigating the natural particulate content of the global background aerosol. The reasons for this are (a) the low level of human activity, (b) the lack of exposed rock and soil, as $98 \%$ of Antarctica is covered by snow and ice, (c) lack of vegetation, and (d) the ice cover of much of the surrounding oceans restricts the contribution of marine-derived particulates to the margins of the continent. This lack of local source areas implies that particles are transported great distances and should represent the "end point" of the atmospheric particulate mass (Hogan 1975).

Shaw (1979) suggests that particles derived from outside Antarctica are not readily transported there due to the great distances involved, the inefficiency of meridional diffusion, and the removal by the frequent and severe storms associated with the Antarctic polar front. The particulates deposited on the Antarctic ice sheet and preserved within the ice layers provide an opportunity to investigate the effect of accumulation rates and distance of transport on their concentration.
Near-surface samples collected at seven Antarctic sites (Fig.1) have been analyzed for microparticle concentration and size distribution. The relationship between particle concentration and accumulation under present climatic conditions is investigated. The size distributions are compared among all seven sites. Conclusions are drawn from these data about the degree to which changes in accumulation may account for significantly enhanced particle concentrations found in snow deposited near the end of the last major glacial stage, the Wisconsin (Thompson and MosleyThompson 1981).

\section{SAMPLING AND LABORATORY PROCEDURES}

A1l analyses were of snow and firn samples and, therefore, several points of caution are necessary. Contamination is potentially a greater problem with more porous firn samples. The mícroparticle data presented here cover a minimum of 10 years at each site, but the precise time intervals represented by each profile are not equivalent due to different dates of sample collection. Consequently, all discussions employ average concentrations and size distribution. The effect of post-depositional diagenetic processes upon the microparticle data is not considered.

With the exception of the Dome $C$ pit samples, a11 samples were cut from snow and firn cores which were transferred frozen to The Ohio State University microparticle laboratory. The snow and firn cores were cut into 40 to $80 \mathrm{~mm}$ samples (sample size being largely a function of the annual accumulation at a given site) and transported to the clean room, where a $45 \mathrm{~mm}$ diameter plug was drilled from the center of each sample with a polyethylene hand corer. This procedure provides a sample which has not been in contact with the core driller or the shipping container. The Dome $C$ pit samples were collected along a pit wall using a plastic $40 \mathrm{~mm}$ diameter syringe and shipped in plastic bottles ( $P a l a i s$ personal communication). All snow and firn surface samples were analyzed within one year after collection.

A11 concentrations and size distributions were determined by multi-channel TAII Coulter counters under class -100 clean room conditions. Insoluble particulates are counted in 14 size ranges from 0.63 to $12.8 \mu \mathrm{m}$ diameter. The total concentration of microparticles is defined as the total number $20.6 \mu \mathrm{m}$ diameter per 500 ul of liquid sample. 


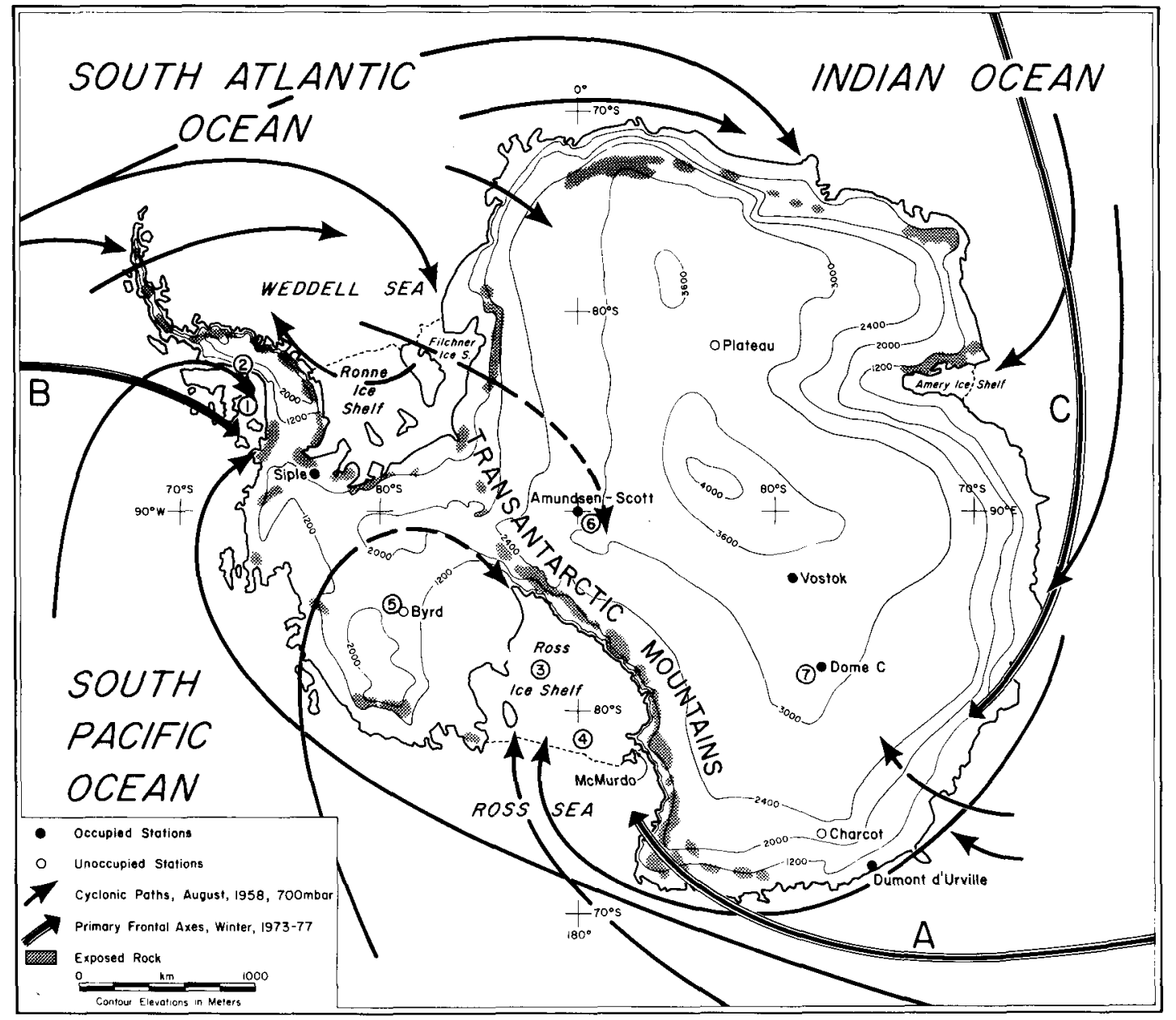

Fig.1. Location of Antarctic surface sampling sites: (1) Monteverdi Peninsula, (2) snow-field above Horse Bluff, (3) base camp on RIS, (4) Q-13 on RIS,

(5) Byrd station strain network, (6) South Pole station, (7) Dome C. The very heavy lines locate the mean winter position of the major frontal axes (Carleton 1981) which occur in association with the long wave troughs. The lighter arrows trace IGY observations of cyclonic paths during August 1958 (Alt and others 1959).

\section{DISCUSSION OF THE DATA}

Figure 1 illustrates the location of each sampling site and Table I presents a summary of all pertinent information. The particle concentrations per $500 \mu l$ sample are averaged over the entire length of each core or core section. For each site, the estimated annual accumulation rate is used to calculate the number of particles (diameter $>0.63 \mu \mathrm{m}$ ) deposited annually.

Figure 2 illustrates microparticle concentrations in two shallow cores from a high accumulation $\left(\approx 910 \mathrm{~kg} \mathrm{~m}^{-2} \mathrm{a}^{-1}\right)$ area $\left(72^{\circ} 30^{\circ} \mathrm{S}, 72^{\circ} 50^{\prime} \mathrm{W}\right)$ in the Antarctic Peninsula (site 1 in Figure 1). Summer melt here is quite low as the lack of ice lenses indicates. The two cores are separated by a horizontal distance of $5 \mathrm{~m}$, yet particle concentration peaks can be traced easily between them. Since during drilling, firn cores tend to break along stratigraphic features, it is impossible on the basis of these data to distinguish whether these distinct microparticle peaks represent original depositional horizons or contamination on the ends of the individual core sections which might have occurred during drilling or transport of the cores.

Microparticle concentrations in two cores from a snow-field above Horse Bluff $\left(71^{\circ} 18^{\prime} \mathrm{S}, 67^{\circ} 29^{\prime} \mathrm{W}\right)$ on the Antarctic Peninsula (site 2 in Figure 1) are shown in Figure 3. Annual accumulation here is much less ( $\left.2220 \mathrm{~kg} \mathrm{~m}^{-2} \mathrm{a}^{-1}\right)$ than at site 1 and summer melting is substantial as indicated by the numerous ice lenses. The microparticle concentration tends to be lower in those sections composed of ice than in adjacent firn segments, suggesting that the particles are left behind in the firn layers during the melting and refreezing process. Even though the cores are separated horizontally by onty $5 \mathrm{~m}$, it is difficult to match individual particle concentration peaks in them as the depositional stratigraphy has been confused by a combination of processes including the percolation of melt water, deflation, and the redistribution of snow.

Surface cores were analyzed from two sites on the Ross Ice Shelf (RIS), $0-13\left(78^{\circ} 57^{\prime} \mathrm{S}, 179^{\circ} 55^{\prime} \mathrm{E}\right)$ and base camp $\left(\approx 82^{\circ} 30^{\prime} \mathrm{S}, 166^{\circ} \mathrm{W}\right)$. Two upper sections

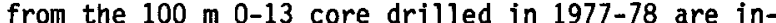
cluded in this study (Table I). The average annual rate of microparticle deposition was $820 \times 10^{7}$ particles $\mathrm{m}^{-2} \mathrm{a}^{-1}$ at $\mathrm{Q}-13$, where accumulation is roughly $180 \mathrm{~kg} \mathrm{~m}^{-2} \mathrm{a}^{-1}$. Microparticle concentrations in two $5 \mathrm{~m}$ cores drilled in 1974 from base camp were analyzed (Mosley-Thompson and Thompson 1982). At base camp, accumulation is approximately $90 \mathrm{~kg} \mathrm{~m}^{-2} \mathrm{a}^{-1}$, one-half that at $\mathrm{Q}-13$, and the number of microparticles deposited annually is 


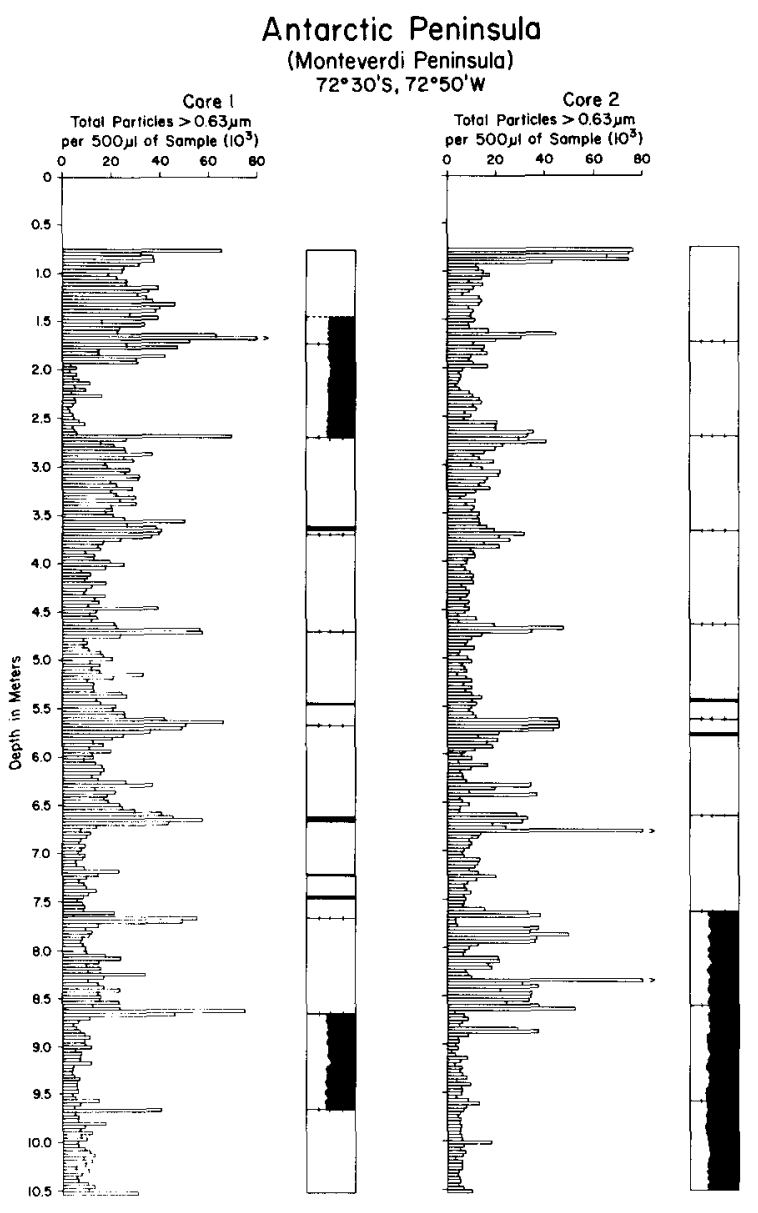

Fig.2. Microparticle concentration profiles for two $5 \mathrm{~m}$ cores $5 \mathrm{~m}$ apart on Monteverdi Peninsula (site 1 in Figure 1). Particle peaks can be traced from one core to the other. However, they are associated with the ends of individual core sections as indicated by tick marks. The stratigraphy on the right illustrates ice layers (solid black) and melting in transport to the laboratory (half black).

$\approx 150 \times 10^{7}$ particles $\mathrm{m}^{-2}, 5.5$ times fewer than at site $Q-13$. Base camp is $\approx 500 \mathrm{~km}$ from the seaward margin of RIS while site $0-13$ is $\approx 180 \mathrm{~km}$ from the open water (sites 4 and 3 in Figure 1). Annually, this distance varies greatly with the seasonal growth and decay of sea ice, which effectively doubles the area of Antarctica. These large changes in sea-ice extent may affect storm track paths and create seasonal variations in the predominant source of the particles deposited at these sites.

The primary mechanism of particulate deposition on RIS is probably associated with dissipating cyclones. Meteorological data collected during the International Geophysical Year 1957-58 (IGY) identified the Ross Sea area as a major center of cyclolysis. Recently, satellite observations of cloud vortices (Carleton 1979) confirm that the Ross Sea sector $\left(160^{\circ} \mathrm{E}-160^{\circ} \mathrm{W}\right)$ is a major graveyard for cyclones generated along the primary frontal axis extending from the Indian Ocean through the Pacific south of Australia and onto RIS (A in Figure 1).

Not only are annual particle concentrations substantially less at $\mathrm{J}-9$, but the number of larger particles (diameters $>1.0 \mu \mathrm{m}$ ) expressed as a per cent of the total is less (24\%) than at $Q-13$ (30\%). Assuming an Antarctic source for the large particles, this suggests that $0-13$ is closer to the source area than J-9. Warburton and Linkletter (1978) analyzed $\mathrm{RIS}$ snow samples for $\mathrm{Mg}, \mathrm{Na}$, and $\mathrm{K}$. Samples closer to

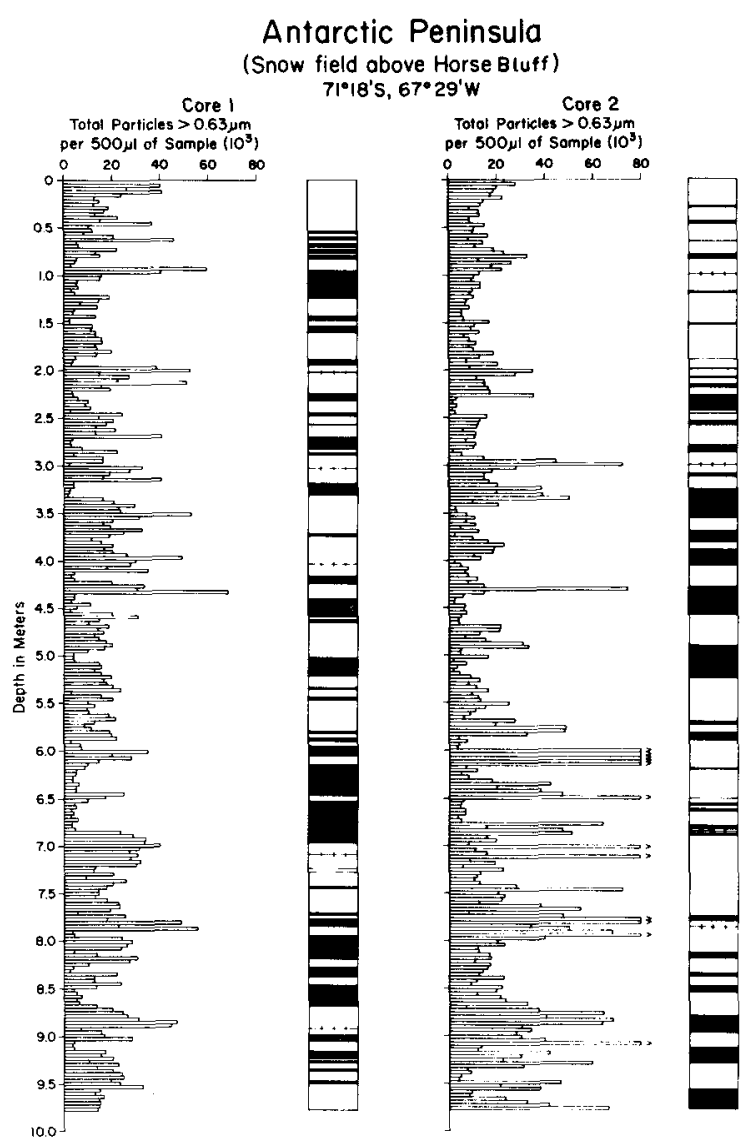

Fig.3. Microparticle concentration profiles from two $5 \mathrm{~m}$ cores $5 \mathrm{~m}$ apart from a snow-field above Horse Bluff, Antarctic Peninsula (site 2 in Figure 1 ). Percolation of melt water has confused the particle records so correlative peaks can not be identified. The stratigraphy on the right fllustrates ice layers (black) which generally correspond to low particle concentrations.

the ice front of RIS exhibit near-marine ionic ratios, but south of Roosevelt Island (Fig.1) enrichments of $\mathrm{Mg}$ and $\mathrm{K}$ suggest the influence of a fractionated marine aerosol and a second, continental, source.

Microparticle concentration data from three inland locations are presented in Table 1 . The concentrations in the 2.5 to $3.3 \mathrm{~m}$ section of the $905 \mathrm{~m}$ Dome $C$ core are nearly identical to concentrations in samples from three $3 \mathrm{~m}$ pits at Dome $C$. Of the seven sampling sites, the lowest microparticle deposition rate is $\approx 80 \times 10^{7}$ particles $\mathrm{m}^{-2} \mathrm{a}^{-1}$ at Dome C, which is $3240 \mathrm{~m} \mathrm{a.s.1.} \mathrm{and} \mathrm{over} 1000 \mathrm{~km}$ from the Antarctic coast.

Samples were analyzed from two firn cores collected along the Byrd station strain network. The average particle deposition rate on the West Antarctic plateau near Byrd station (1 $531 \mathrm{~m}$ a.s.1.) is $490 \times 10^{7}$ particles $\mathrm{m}^{-2} \mathrm{a}^{-1}$, which is $60 \%$ the rate at $0-13$ and three times that at the RIS base camp.

A $100 \mathrm{~m}$ core was drilled in 1974 at the South Pole and and analyzed in detail for microparticle concentration and size distribution (Mosley-Thompson 1980). Samples from the 4 to $6 \mathrm{~m}$ section, below the 1956 reference horizon, yield an annual particle deposition rate of $190 \times 10^{7}$ particles $\mathrm{m}^{-2} \mathrm{a}^{-1}$, similar to that at base camp.

For comparison with these Antarctic deposition rates, similar calculations (Table I) were made for samples collected from two tropical glaciers where locally derived material constitutes the major particulate source. These two glaciers are Quelccaya ice 
Thompson and Mosley-Thompson: Spatial distribution of microparticles within snow-fall

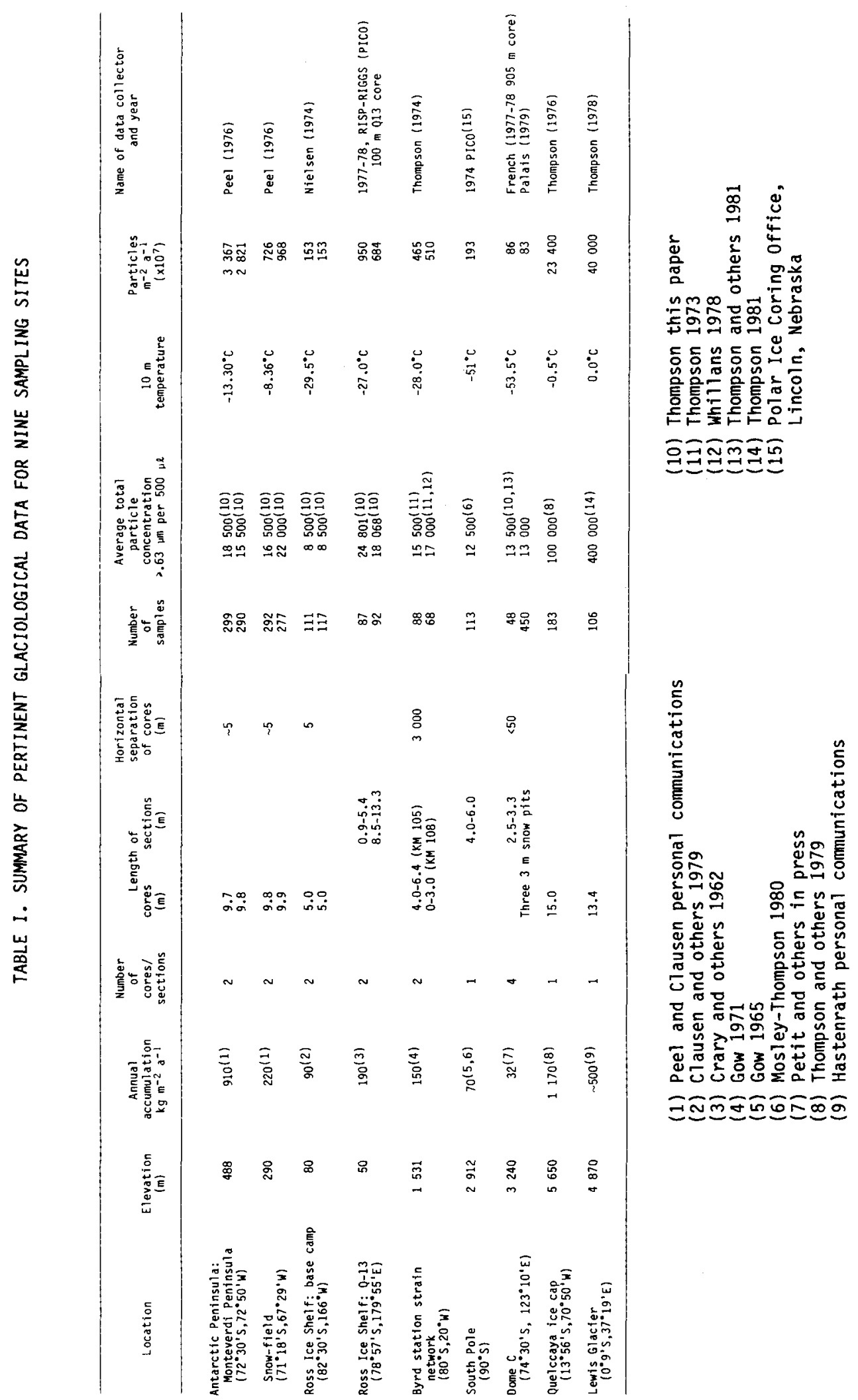




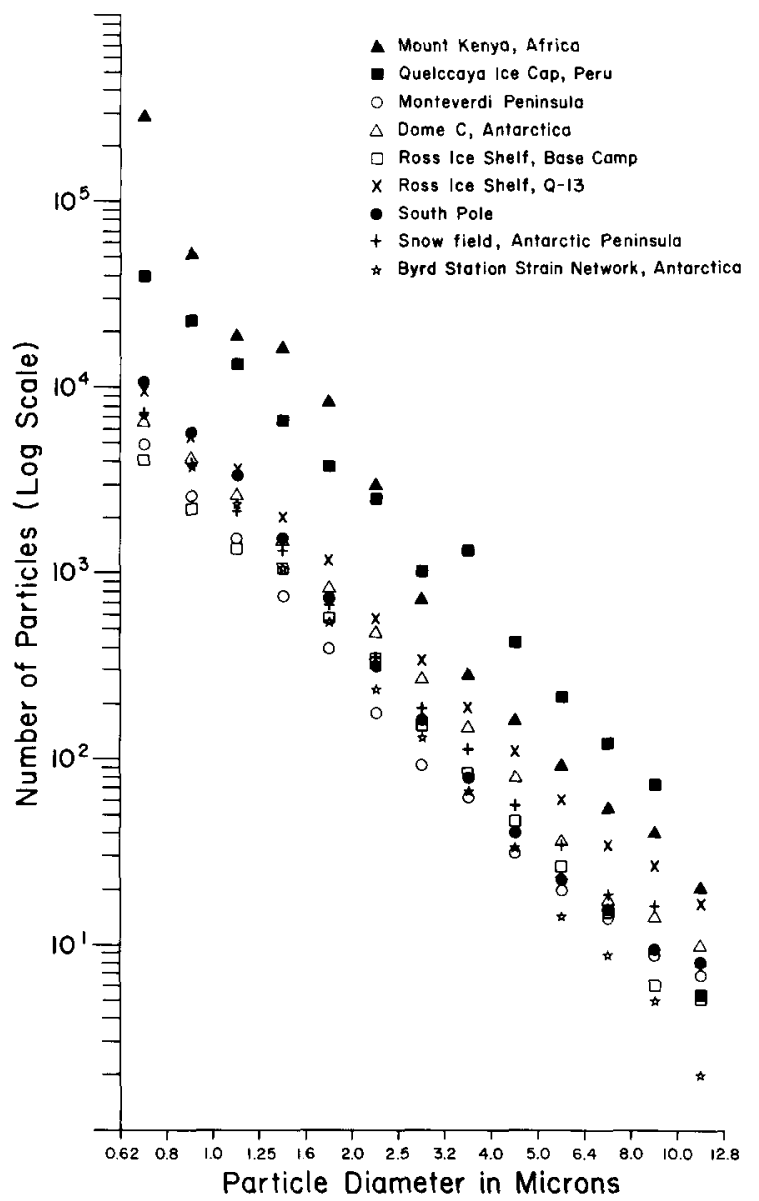

Fig.4. Average size distribution for 40 consecutive samples from each of seven Antarctic sampling sites and from two tropical sites, Quelccaya ice cap and Lewis Glacier, where locally derived material is abundant.

cap in the southern Andes of Peru and Lewis Glacier on Mt Kenya, East Africa.

The size distribution of a population of particles provides information about the proximity to the source area. Figure 4 presents the average size distribution for seven Antarctic sites and two tropical glaciers. These were calculated by averaging the number of particles in each of the 14 size ranges measured in $20 \mathrm{ml}$ of melt water ( 40 consecutive $500 \mu \ell$ samples) from each sampling site. The size distributions of samples from Antarctic sites are remarkably similar in contrast to the poorly sorted particle distributions measured on Quelccaya ice cap and Lewis Glacier.

\section{DISCUSSION AND CONCLUSIONS}

To understand fully microparticle deposition at a given site it is essential that the characteristics of dominant atmospheric circulation patterns and local boundary layer conditions be understood. This cursory investigation of current microparticle deposition at seven Antarctic sites serves to illustrate the difficulties encountered when attempting to infer past atmospheric conditions from the microparticles deposited within the large ice sheets.

The first step is to distinguish locally derived material from background or "global" particulate mass. Locally derived material should be less well sorted and contain a greater fraction of larger fragments. Natural tropospheric aerosols range in radius between 0.1 and $20.0 \mathrm{\mu m}$ (Junge 1977) and the sett]ing effect of gravity is negligible for particles
$<1.0 \mathrm{~mm}$. The particle size distribution data presented in this paper suggest that the particulates deposited at both inland and coastal Antarctic sites are well sorted with very low numbers of larger particles $(>1.0 \mu \mathrm{m})$. Inspection of Figure 4 reveals that Q-13 may be an exception as it exhibits a size distribution which, for particles with diameters $>2.5 \mu \mathrm{m}$, more closely resembles that of tropical ice caps. This indicates the contribution of a local source, probably the exposed areas on Ross Island and aiong the coast of east Antarctica (Fig.1). Certainly at each site the contribution from local source areas will be dependent on local wind velocities and directions.

In general, sampling sites closer to the coast exhibit a greater rate of microparticle deposition ranging from $3000 \times 10^{7}$ particles $\mathrm{m}^{-2} \mathrm{a}^{-1}$ at Monteverdi Peninsula (Fig.1) to $800 \times 10^{7}$ particles $\mathrm{m}^{-2} \mathrm{a}^{-1}$ at both Horse Bluff snow-field and $\mathrm{Q}-13$. Results from base camp are anomalous ( $\approx 150 \times 10^{7}$ particles $\mathrm{m}^{-2} \mathrm{a}^{-1}$ ), reflecting the rapid removal of material as dissipating cyclones move inland across RIS. These attempts to interpret the microparticle records illustrate the importance of detailed synoptic observations.

The effect of local accumulation rate upon (a) deposition of microparticles and (b) concentration and/or dilution of deposited material is another aspect which warrants investigation. It is unknown what percentage of insoluble particulates are deposited within snow and ice crystals and what percentage arrive at the surface as dry fallout. Assuming for the sake of argument that the variability of dry fallout is negigible, we examine the data in Table I for South Pole and Dome $C$. The ratio of accumulation at South Pole to Dome $C$ is 2.19 and the ratio of particle deposition is 2.26 , suggesting that under current atmospheric conditions a doubling of accumulation within a year also doubles the particles deposited. Of course, this assumes identical meteorological conditions and an equal dry fallout contribution.

A similar comparison between the two sites on the Antarctic Peninsula gives a ratio of 4.14 for the accumulation and 3.65 for the ratio of particle deposition rates. Given these simplifying assumptions, these data indicate that greater accumulation tends to be associated with greater annual particulate deposition. Figure 5 illustrates that the relationship between annual particle deposition and distance from the coast is analogous to the relationship between annual water accumulation and distance from the coast.

The purpose of this study is two-fold. First, the data presented represent all the Antarctic sites where surface microparticle measurements have been conducted. Particle concentrations are shown to be

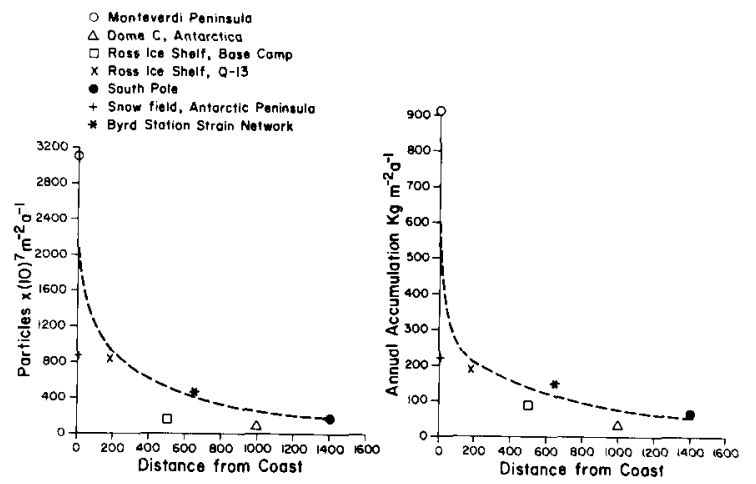

Fig.5. The left diagram represents the relationship between particle concentrations and distance from the coast for seven Antarctic sample sites. On the right is the plot of annual water accumulation vs distance from the coast for each location. 
inversely related to the distance from the source, and the use of size distribution for identifying the contribution of local sources is demonstrated. Second, these data illustrate the need for a better understanding of the mechanisms controlling microparticle deposition in Antarctica.

Data presented by Thompson and Mosley-Thompson (1981) and Thompson and others (1981) do not support a change in net accumulation as the mechanism producing the great increases in microparticles within the late glacial (Wisconsin) ice in the $905 \mathrm{~m}$ Dome $C$, Antarctica core. An increase in the particulate loading of the atmosphere and a greater contribution by dry fallout are suggested to account for the substantial increase in microparticles. Earlier microparticle analysis of sections from Byrd station, Antarctica, and Camp Century, Greenland, deep ice cores (Thompson 1977) revealed great increases in particle concentrations associated with the ice deposited during the Wisconsin glacial stage. Koerner (1977) reports very high dust content within the Wisconsin ice of the $299 \mathrm{~m}$ Devon Island ice cap core. For both the Camp Century and Byrd cores, Cragin and others (1977) report substantial increases in the concentrations of alkali and alkaline earth elements in the late glacial ice. These studies have invoked one or all of the following mechanisms to account for these increases: (1) changes in the annual accumulation, (2) changes in the concentration of material suspended in the atmosphere, and (3) alteration in the type of precipitation (e.g. ice crystal vs storm).

In order to facilitate the interpretation of microparticle data from firn and ice cores it is critical that a sound theoretical basis and realistic empirical framework be developed on the basis of the current microparticle depositional pattern and concurrent measurements of atmospheric particulate concentrations. The microparticle records contained within the large ice sheets provide the only available high-resolution record of past atmospheric characteristics. Consequently, it behoves us to construct a microparticle data base for future expansion and continual re-interpretation as more microparticle data and longer and better synoptic records become available. Eventually these data will provide the proper climatic explanation for the substantial variations in microparticle concentrations and size distributions recorded within the deep ice cores.

\section{ACKNOWLEDGEMENTS}

The authors wish to express appreciation to $D$ Peel of the British Antarctic Survey, J Nielson of the University of Copenhagen, and J Palais of Ohio State University for their efforts in collecting firn cores and pit samples. We thank illustrator Bob Tope for the diagrams used in this manuscript and Jean Cothran for typing it. We express gratitude to the U.S. National Science Foundation and the Ohio State University for support of microparticle research over the past seven years.

\section{REFERENCES}

Alt J, Astapenko P, Ropar N J Jr 1959 Some aspects of the Antarctic atmospheric circulation in 1958. IGY General Report Series 4

Carleton A M 1979 A synoptic climatology of satellite-observed extratropical cyclone activity for the southern hemisphere winter. Archiv für Meteorologie, Geophysik und Bioklimatologie Ser B $27(4): 265-279$
Carleton A M 1981 Monthly variability of satellitederived cyclone activity for the southern hemisphere winter. Journal of Climatology 1(1): 21 38

Clausen H B, Dansgaard W, Nielsen J 0, Clough J W 1979 Surface accumulation on Ross Ice Shelf. Antaretic Journal of the United States 14(5): 68-72

Cragin $\mathrm{J} \mathrm{H}$, Herron $M \mathrm{M}$, Langway $\mathrm{C} \mathrm{C} \mathrm{Jr,} \mathrm{Klouda} \mathrm{G}$ 1977 Interhemispheric comparison of changes in the composition of atmospheric precipitaion during the late Cenozoic era. In Dunbar Maxwell J (ed) Polar oceons. Proceedings of the polar oceans conference, Montreal 1974. Calgary, Arctic Institute of North America: 617-631

Crary A P, Robinson $E S$, Bennett $H F$, Boyd $W W J r$ 1962 Glaciological regime of the Ross Ice Shelf. Joumal of Geophysical Research 67(7): 2791-2807

Gow A J 1965 On the accumulation and seasonal stratification of snow at the South Pole. Journal of Glaciology 5(40): $467-477$

Gow A J 1971 Depth-time-temperature relationships of ice crystal growth in polar glaciers. CRREL Research Report 300

Hogan A W 1975 Antarctic aerosols. Joumal of Applied Meteorology 14(4): 550-559

Junge C E 1977 Processes responsible for the trace content in precipitation. International Association of Hydrological Sciences Publication 118 (General Assembly of Grenoble 1975 - Isotopes and Imourities in snow and Ice): 63-77

Koerner R M 1977 Distribution of microparticles in a 299-m core through the Devon Island ice cap, Northwest Territories, Canada. International Asssociation of Hydrological Sciences Publication 118 (General Assembly of Grenoble 1975 - Isotopes and Impurities in Snow and Ice): $371-376$

Mosley-Thompson E 1980911 years of microparticle deposition at the South Pole: a climatic interpretation. Ohio State University. Institute of Polar Studies. Report 73

Mosley-Thompson E, Thompson L 1982 Microparticle analys is of the Ross Ice Shelf Q-13 core and preliminary results from the $J-9$ core. Annals of Glaciology 3: 211-215

Petit J R, Jouzel J, Pourchet M, Merl ivat L In press. Spatial and temporal changes of accumulation and stable isotope content in the Dome $C$ area (Antarctica). Journal of Geophysical Research

Shaw GE 1979 Considerations on the origin and properties of the Antarctic aerosol. Reviews of Geophysics and Space Physics 17(8): 1983-1998

Thompson L G 1973 Analysis of the concentration of microparticles in an ice core from Byrd. station, Antarctica. Ohio State University. Institute of Polar Studies. Report 46

Thompson L G 1977 Variations in microparticle concentration, size distribution and elemental composition in Camp Century, Greenland, and Byrd station, Antarctica, deep ice cores. International Association of Hydrological Sciences Publication 118 (General Assembly of Grenoble 1975 - Isotopes and Impurities in snow and Ice): 351-364

Thompson L G 1981 Ice core studies from Mt Kenya, Africa, and their relationship to other tropical ice core studies. International Association of Hydrological Sciences Publication 131 (Symposium at Canberra 1979 - Sea level, ice and climatic change): $55-62$

Thompson L G, Mosley-Thompson E 1981 Microparticle concentration variations 1 inked with climatic change: evidence from polar ice cores. Science 212(4496): 812-815

Thompson L G, Hastenrath S, Morales Arnao B 1979 Climatic ice core records from the tropical Quelccaya ice cap. Science 203(4386): $1240-1243$ 
Thompson L G, Mosley-Thompson E, Petit J R 1981 Glaciological interpretation of microparticle concentrations from the French 905-m Dome $C$, Antarctica core. Intemational Association of Hydrological Sciences Fublication 131 (Symposium at Canberra 1979 - Sea level, ice and climatio change): 227-234

Warburton J A, Linkletter G 01978 Atmospheric processes and the chemistry of snow on the Ross Ice Shelf, Antarctica. Journal of Glaciology 20(82): 149-162

Whillans I M 1978 Surface mass-balance vari-

ability near "Byrd" station Antarctica, and its

importance to ice core stratigraphy. Journal of Glaciology 20(83): 301-310 